\title{
Correction to: Increased Salivary IgA Response as an Indicator of Immunocompetence After a Mindfulness and Self-Compassion-Based Intervention
}

\author{
Miguel Bellosta-Batalla $^{1}$ - Nicolás Ruiz-Robledillo ${ }^{1} \cdot$ Patricia Sariñana-González $^{1}$. \\ Thaïs Capella-Solano $^{2}$ - Sara Vitoria-Estruch ${ }^{1} \cdot$ Gemma Hidalgo-Moreno $^{1}$. \\ Josefa Pérez-Blasco $^{3}$ • Ángel Romero-Martínez ${ }^{1} \cdot$ Luis Moya-Albiol $^{1}$
}

\section{Correction to: Mindfulness}

https://doi.org/10.1007/s12671-017-0830-y

The authors would like to acknowledge an error in the results section of this paper. Figures 1 and 2 are inverted. Figure 1 shows the increase of salivary IgA levels and Figure 2 shows the decrease of salivary cortisol levels. This error has no implications for the results, data in the text are correct. Updated figures appear below. The original article has been corrected.

The online version of the original article can be found at https://oi. org/10.1007/s12671-017-0830-y

Luis Moya-Albiol

Luis.Moya@uv.es

1 Department of Psychobiology, University of Valencia, Avda. Blasco, Ibañez, 21, 46010 Valencia, Spain

2 Centro de Psicología Psyke, C/Matías Perelló, 60, 46005 Valencia, Spain

3 Department of Evolutionary and Educational Psychology, University of Valencia, Avda. Blasco Ibañez, 21, 46010 Valencia, Spain

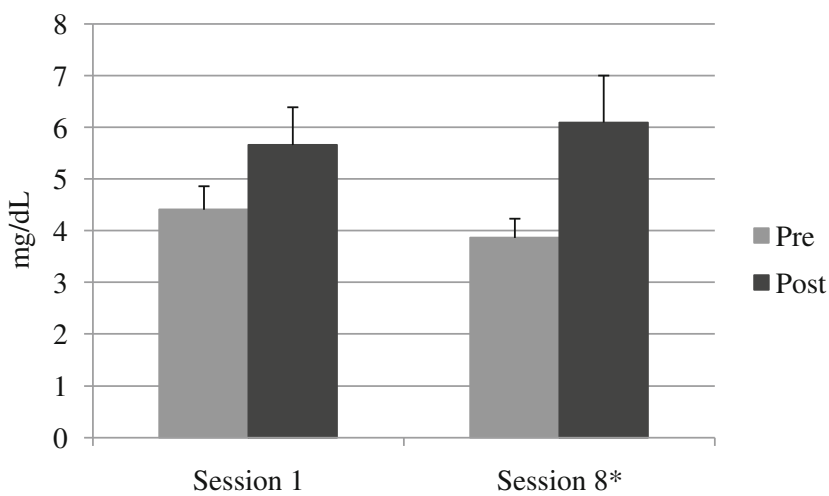

$* p<.012$

Fig. 1 Salivary IgA levels before and after the first and the last session of the intervention

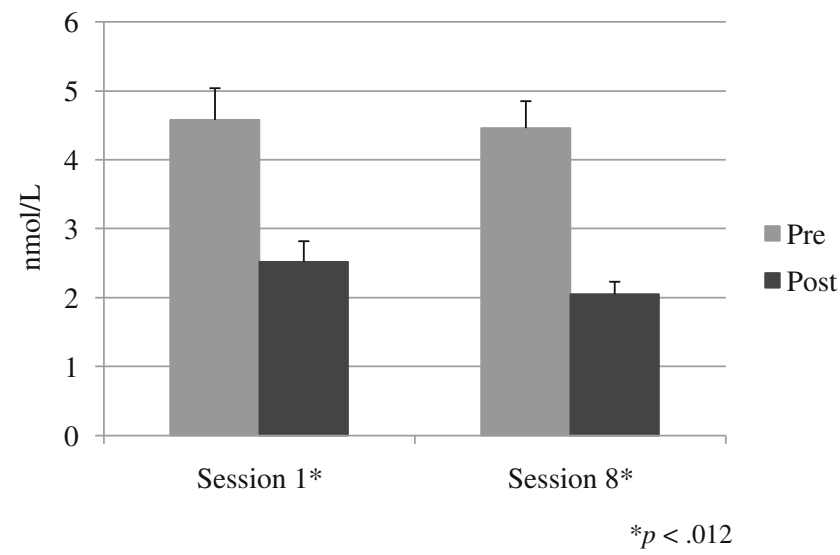

Fig. 2 Salivary cortisol levels before and after the first and the last session of the intervention 